\title{
Koro, psychological retraction of the genitalia: A case series
} A Ellepola

\section{Abstract \\ Koro has been found to exist mainly in Asia and Africa. Some authors describe the syndrome as a universal syndrome, rather than a condition found only in certain cultures. It is not uncommon to find koro presenting with comorbid conditions and psycho- pathology relevant to these conditions. The cases in this article illustrate three different presentations of Koro in Sri Lanka, where the affected males believed that their worth was associated with fertility and}

sexual potency. One patient had comorbid schizophrenia, and other two had anxious personality traits.

Key words: koro, culture-bound syndromes, anxiety, genitalia

SL J Psychiatry 2021; 12(2): 41-43

\section{Introduction}

Culture-bound syndromes are folk ailments unique to certain cultures, where alterations of behavior are found to be prominent (1). A majority of such conditions are not syndromes, they are traditional, cultural and local ways of responding to distress or stress (1).

Koro is a culture bound syndrome in which the affected individual believes that the genitalia is shrinking, retracting or vanishing (2). Affected person strongly believe that their genitalia are shrinking which leads to impotence, sterility and eventual death (2). There are rare cases where affected females believe that her breasts and/or labia are shrinking $(2,9)$. Koro has been described in China and other cultures in Asia and Africa (2). The disorder is especially prevalent in cultures in which reproductive ability is a major determinant of a young mans' worth (2).

Culture bound syndromes often have associations with other psychiatric disorders $(4,7)$. Patients suffering from koro may have comorbid psychiatric conditions and associated psychopathology (4). Some take remedial actions by tying the penis with strings to an object, or getting others help (9). There are possible interactions between culture and psychopathology (8). The firm belief may take the form of a delusion, overvalued idea or an oedipal castration anxiety, especially when there is a male dominant cultural significance. However, koro is usually an anxiety state and not delusional (9). The syndrome may occur in individual patients or as an epidemic (9). Koro epidemics have been described in cultures in
Thailand (rok joo) and India (jinjina bemar) (9). Features of koro have been described in western cultures among patients with other psychiatric morbidities such as anxiety, depression and schizophrenia $(10,11,12)$.

The three case reports describe different presentations and associations of koro in the Anuradhapura district, Sri Lanka. Two patients were males who believed that masculinity is strongly associated with sexual and reproductive potency.

\section{Case Report 1}

A 30-year old recently married taxi driver from Anuradhapura, Sri Lanka presented to a psychiatrist in the private sector, with a week's history of persistent, severe anxiety about his penis shrinking into the abdomen. He had asked his wife several times to keep pulling his penis to prevent it getting retracted. He also experienced anticipatory anxiety prior to coitus with his wife. He suffered from insomnia, lethargy, lack of interest and fear of death as a consequence of the belief about the retracting penis.

He had married his 23-year old wife 2 months back, and had experienced erectile failure and premature ejaculation on a number of occasions. He was preoccupied with distressing thoughts about sexual dysfunction, and showed features of extreme anxiety and an adjustment response. He believed that a marriage and his maleness were useless unless he had good erection and fertility. His anxiety about being unable to have children in the future was very marked. His premorbid personality was 
anxious and avoidant. He had been treated with fluoxetine for premature ejaculation at the age of 22 years. There was no history of substance abuse or co-morbid depression.

His brief belief was not delusional, and was more anxiety related. His presentation suggested that his anxious personality traits, and worries regarding sexual identity and sexual dysfunction may have acted as predisposing and precipitating factors for his current condition. A short course of benzodiazepines and counseling proved to be effective treatment.

\section{Case Report 2}

A forty-year old single, unemployed male who was diagnosed and on treatment for schizophrenia presented with a firm belief that his penis was vanishing into his abdomen for one month. He had attempted to prevent the disappearance of his genitalia by tying his penis with pieces of cloth. He had become anxious and agitated since the onset of these symptoms. It was not possible to shake his belief by argument or provision of reassurance. His strong, unshakable belief was compatible with a delusion. His belief was systematized and also related to other beliefs, for example regarding nonexistence of his penis, infertility, erectile problems and death as a result of the vanishing penis.

His illness had started at the age of 20 years. He had experienced four relapses over the past 20 years, with erratic medication compliance. He had been prescribed intramuscular and oral antipsychotics. His previous psychotic symptoms included auditory hallucinations, persecutory delusions and beliefs regarding external control of his thoughts. He had a forensic history due to exhibitionism five years previously. He had never experienced features of koro prior to the current presentation. He reported recent use of cannabis, which may have precipitated the recent symptoms. Optimization of the antipsychotic treatment regimen helped to relieve his condition.

\section{Case Report 3}

A 38-year old divorced man presented to the psychiatry outpatient clinic with severe anxiety and depressive features for one month. He had a distressing belief that his penis was disappearing at night. He believed that his genitalia were retracting into his abdomen, causing erectile impotence and nocturnal emission of semen. He had tried several mechanical means to stop the penile retraction. He had a strong fear that he would soon die as a result of this problem. He developed features of anxiety, including panic attacks and depression in this context.
He had a past history of alcohol dependence, social anxiety and erectile dysfunction. He had sought psychiatric help in the past, but with poor engagement with the management plans. His wife had left him eight years back, and he had been able to stop his alcohol dependence with medical help. His premorbid personality revealed anxiety traits from childhood. He had been a shy student who was never involved in public performances. He had been bullied during his childhood. He had received no formal teaching about human sexuality as a student. He believed several sexual myths including the belief that masturbation caused loss of energy.

The development of features of koro in this patient are likely to have been linked to his anxiety traits, sexual beliefs and erectile dysfunction. Treatment included a short course of benzodiazepines and counseling. The patient attended follow up clinics and recovered from the condition.

\section{Discussion}

Koro is characterized by several symptoms including belief of retraction of the penis into the abdomen, its' potential lethality and intense anxiety (13). Feelings of sexual inadequacy, sexual myths and sexual practices may contribute to the disorder (14). Psychodynamic and anthropological precipitants such as financial problems have been described for this condition (15). The course of koro is usually brief and self-limiting. Few reported koro-like cases had been chronic, needing intense interventions (16).

Two of the three cases of this article were associated with significant long-term anxiety. Both these patients had anxious personality traits. Sexual dysfunction was a marked feature. Beliefs about masculinity and sexuality seem to have contributed to the onset of the disease in these patients. Both men recovered within a short period of time with counseling and benzodiazepines and had no residual symptoms.

The other case of koro had an underlying psychosis. It could be justified as a koro-like condition, since the patient developed the delusion in the context of relapse of his psychiatric disorder. He had a history of cannabis use, and a past history of exhibitionism. This patient took a longer time to recover from his symptoms, including the koro-like features.

All the three males had classical features of koro; belief about penile retraction, associated anxiety and fear, and attempts to prevent the disappearance of genitalia. One patient was married, whereas the other two were single. They all sought medical help to relieve their symptoms. 


\section{Conclusions}

It is important to explore for premorbid personality and other associated conditions in culture-bound disorders. Although very distressing to the individual, it is most often a brief, self-limiting condition with no residual symptoms, when there's no major underlying illness.

\section{Declaration of interest}

None.

A Ellepola, Teaching Hospital, Anuradhapura, Sri Lanka

Corresponding author: A Ellepola

Email: Anu.ellepola@gmail.com

fid http://orcid.org/0000-0001-9699-2777

\section{References}

1. Simons RC. Introduction to Culture-Bound Syndromes. Psychiatr. Times. Nov 2001; 11 (18).

2. Mattelaer JJ, Jilek W. Koro-the psychological disappearance of the penis. J Sex Med. 2007; 4(5): 150915 .

3. https://herbsformental health.com

4. Sawant NS, Nath A. Cultural misconceptions and associated depression in Dhat syndrome. SLJP 2012; 3 (1): $17-20$.
5. De Silva P, Dissanayake SAW. The loss of semen syndrome in Sri Lanka. A clinical study. J. Sex Marital Ther: 4, 195204.

6. Sumathipala A, Siribaddana SH, Bhugra D. Culturebound syndromes: The story of dhat syndrome. BJPsych 184: 200-9.

7. Patra S, Sidana A, Gupta N. Delusion of dhat: The quandary of the form-content dichotomy. Ind Psychiatry J. 2014; 23(2): 171-2.

8. Elghazouani F, Barrimi M. Koro syndrome: When culture interacts with psychopathology. Rev. Méd. Brux. March 2018; 39(2): 108-10.

9. https://www.sciencedirect.com/topics/neuroscience/koro

10. Berrios GE, Morley SJ. Koro-like symptom in a nonChinese subject. B J Psych 145: 331-4.

11. Ang PC, Weller MP. Koro and Psychosis. B J Psych 1984; 145: 335.

12. Kendall EM, Jenkins PI. Koro in an American man. Am J Psychiatry. 1987; 144: 1621.

13. Fishbain DA, Barsky S, Goldberg M. "Koro" (genital retraction syndrome): Psychotherapeutic interventions. Am J Psychother 1989; 43: 87-91.

14. Emsley RA. Koro in non-Chinese subject. B J Psych. 1985; 146: 102-3.

15. Casagrande JB, Gladwin TW. Anthropological Society of Washington; Normal and Abnormal; the key problem of Psychiatric Anthropology, in some uses of anthropology; Theoretical and applied. pp. 3-48.

16. Kar N. Chronic Koro-like symptoms-two case reports. BMC Psychiatry 2005; 5: 34. 